\title{
Wi-Fi Salvador: mapeamento colaborativo e redes sem fio no Brasil
}

\author{
André Lemos* \\ Leonardo Pastor** \\ Nelson Oliveira***
}

\section{Resumo}

O trabalho faz uma breve demonstração de políticas públicas para inclusão digital por meio da disponibilização do acesso à internet por meio de redes sem fio e discute a forma como as pessoas se relacionam com os lugares, de acordo com a existência ou inexistência de acessibilidade à internet. $\mathrm{O}$ objetivo é discutir o acesso à internet pelas redes sem fio no Brasil e, mais especificamente, na cidade de Salvador. Este trabalho é fruto de pesquisa realizada no âmbito do Grupo de Pesquisa em Cibercidades da Universidade Federal da Bahia e mostra como a intersecção entre o ciberespaço e o espaço físico está trazendo novas experiências de uso e de produção de sentido sobre a cidade. Hoje, a urbe contemporânea supõe ampla conexão e associações entre espaço físico e "territórios informacionais" para os mais diversos fins, em uma aliança entre a mobilidade física e a informacional. Assim, mostramos os principais desafios teóricos em jogo com as mídias digitais, as redes sem fio e o espaço urbano. A partir deste aporte, o trabalho faz uma análise do projeto Wi-Fi Salvador, o maior mapeamento de redes sem fio já realizado na capital baiana e no Brasil.

Palavras-chave: Cibercultura. Cidades digitais. Mapeamento colaborativo. Mobilidade. Redes sem fio.

\footnotetext{
* Professor associado do Programa de Pós-Graduação em Comunicação, Departamento de Comunicação Social, Faculdade de Comunicação(Facom) da Universidade Federal da Bahia (UFBA), Salvador, BA, Brasil. Doutor em Sociologia pela Université Paris V, Sorbonne, Pesquisador do CNPq. E-mail: alemos@ufba.br. ** Bolsistas do PET/Facom/UFBa, pesquisadores do Grupo de Pesquisa em Cibercidade (GPC/POSCOM/UFBA), estudantes de jornalismo da Facom/UFBa - Salvador, BA, Brasil. E-mail: leopbr@gmail.com.

*** Bolsistas do PET/Facom/UFBa, pesquisadores do Grupo de Pesquisa em Cibercidade (GPC/POSCOM/UFBA), estudantes de jornalismo da Facom/UFBa - Salvador, BA, Brasil. E-mail: nelson@quattrotratti.com.
} 


\section{Wi-Fi Salvador: collaborative mapping and wireless networks in Brazil}

\section{Abstract}

This article makes a brief demonstration of public policies for digital inclusion through the provision of Internet access via wireless networks and discusses how people relate to places, according to the existence or lack of accessibility to the internet. The paper has the objective to debate the access to internet through wireless networks in Brazil and, more specifically, in the city of Salvador. This work also does a brief demonstration of public wireless networks and debate how people relate with places, according to the existence or inexistence of internet accessibility. This work is the result of a research made on the Group of Research in Cybercitys of University Federal of Bahia and shows how the intersection between the cyberspace and physic space is bringing new experiences of use and production of sense about the city. Today, the contemporary city presume a large connection and associations between the physic space and "informational territories" to a lot of purposes, in an alliance between physic and informational mobility. In that way we show what are the main theoretical challenges at stake with locative medias, the wireless networks and the urban space. This work makes an analysis of the project Wi-Fi Salvador, the biggest online mapping of wireless networks ever made in the capital of Bahia and Brazil.

Key words: Cyberculture. Digital cities. Collaborative mapping. Mobility. Wireless networks.

\section{Wi-Fi Salvador: mapeo colaborativo y redes inalámbricas en Brasil}

\section{Resumen}

En el presente artículo, se hace una breve demostración de las políticas públicas de inclusión digital a través de la provisión de acceso a Internet a través de redes inalámbricas y explica cómo las personas se relacionan a los lugares, de acuerdo con la existencia o falta de acceso a Internet. Pretende discutir el acceso a internet a través de redes inalámbricas en Brasil y, más específicamente, en la ciudad de Salvador. El trabajo también hace una breve demonstración de políticas públicas para inclusión digital a través de la disponibilidad del acceso a internet a través de redes inalámbricas y discute la manera como las personas se relacionan con los lugares, en función de la existencia o ausencia de accesibilidad a internet. Este trabajo es fruto de investigación hecha en el ámbito del Grupo de Investigación en Ciberciudades de la Universidad Federal de Bahía y muestra como la intersección entre el ciberespacio y el espacio físico está trayendo nuevas experiencias de uso y de producción de sentido sobre la ciudad. Hoy, la urbe contemporánea supone amplia conexión y asociación entre espacio físico y territorios informativos para los más diversos fines, en una alianza entre la movilidad física y la informacional. Así, mostramos los principales desafíos teóricos en juego con 
los medios digitales, las redes inalámbricas y el espacio urbano. A partir de esto, el trabajo hace una análisis del proyecto Wi-Fi Salvador, el levantamiento más grande de redes sin fio ya hecho en la capital baiana y en Brasil.

Palabras clave: Ciudades digitales. Cibercultura. Mapeo de colaboración. La movilidad. Las redes inalámbricas.

\section{Introdução}

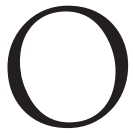

s estudos em comunicação no Brasil e no Mundo tem prestado pouca atenção ao espaço. Privilegiando estudos de efeito de mídia, a ciência da comunicação dedica- se mais à questão do tempo e sua relação com a recepção de produtos midiáticos massivos, como os jornais e a TV. É mesmo sintomático pensarmos que o modelo de Lasswell, que definiu o campo da comunicação, não presta muita atenção à dimensão espacial. Quando esse aparece é apenas como fundo (como, por exemplo, estudos de "Empresas jornalísticas na América Latina" ou "A televisão entre os moradores da cidade X" etc.).

Pouco se pensa na produção midiática do espaço, em como ela reconfigura as relações locais, como ela altera sentidos, práticas e hábitos ancorados em um lugar. Esse deve ser compreendido não apenas como "fundo" abstrato, mas, ao mesmo tempo, como localidade, em sua dimensão física e concreta, criando espaçamentos, e como dimensão de sentido, emergente de prática social, como um "contexto de significados", podendo ser assim simbólico, virtual ou imaginário. Essa discussão ainda engatinha nas Ciências da Comunicação" (FALKHEIMER; JANSSON, 2006; ADAMS, 2009; ITO, MAIER-RABLER, 2004).

Com o amadurecimento da cultura digital, principalmente a partir dos anos 1990, especial atenção tem sido dada, embora ainda de forma incipiente, aos processos de espacialização proporcionados pelas novas tecnologias de informação e comunicação, particularmente com a popularização da internet e das tecnologias digitais móveis e sem fio. Hoje usar um tablet, o twitter, o foursquare, os mapas e o GPS embutidos em smartphone revelam, irredutivelmente, as dimensões locais, sociais e lúdicas da cultura da convergência digital. 
Compreender a comunicação contemporânea, em suas múltiplas facetas, passa não apenas pelas análises do impacto midiático na nossa percepção temporal, mas pelo reconhecimento de que as mídias em geral, e as digitais em particular, produzem relações locais e espaciais específicas que, sem essa perspectiva, a análise comunicacional das tecnologias de informação e comunicação estará incompleta. As mídias móveis, as redes ubíquas, a internet das coisas, apenas amplificam essa importância. $\bigcirc$ momento agora é de apreender a "virada espacial" nos estudos de mídia (FALKHEIMER ; JANSSON, 2006) e particularmente com a cultura da mobilidade dos dispositivos portáteis e redes móveis, com as zonas $\mathrm{Wi}$-Fi, objeto desse artigo.

Nesta pesquisa, buscamos compreender de que forma as redes sem fio produzem processos de espacialização e socialização nas cidades, reconfigurando as relações das pessoas entre si e com os locais. Para isso, apresentamos:

1. as atuais discussões sobre as redes Wi-Fi e como elas são responsáveis por transformar ou criar novas práticas no espaço urbano;

2. um panorama das redes Wi-Fi no Brasil, demonstrando seus usos e projetos;

3. analisamos as novas potencialidades geradas por ferramentas digitais como o mapeamento colaborativo; e,

4. apresentamos o projeto "Wi-Fi Salvador", uma experiência em mapeamento colaborativo pioneira no Brasil.

O texto é descritivo e analítico, mostrando os conceitos de redes sem fio (Wi-Fi), de "territórios informacionais". Faz-se um panorama da infraestrutura de redes sem fio no Brasil, chegando à análise das novas formas de mapeamento colaborativo e o projeto Wi-Fi Salvador. O objetivo do artigo é mostrar a expansão das redes sem fio, a cultura da mobilidade em jogo com as tecnologias móveis de comunicação e informação e destacar a dimensão participativa da cultura digital por meio das experiências de mapeamentos colaborativos. Descrevemos, no final do artigo, o primeiro projeto de mapeamento de redes Wi-Fi no Brasil em uma das maiores capitais brasileiras, Salvador na Bahia. 


\section{Cidade desplugada}

As redes sem fio tornam-se, a cada ano, mais comuns nos espaços públicos e privados. Emerge uma "cidade desplugada" (LEMOS, 2005), que possibilita aos seus cidadãos apropriação dos lugares de diversas formas a partir do uso de tecnologias móveis. A rede é ubíqua. Mesmo no Brasil, o fenômeno das zonas de acesso à internet sem fio torna-se mais comum, seja em grandes ou pequenas cidades. A mais popular está relacionada ao Wi-Fi, termo utilizado como abreviação de "wireless fidelity" (802.11b wireless local area networking - WIRELESS GLOSSARY, 2005). Seguindo outros países, o Brasil começou a ter bons exemplos de experiências com $\mathrm{Wi}$-Fi em locais públicos, a partir de iniciativas dos governos e prefeituras. É possível, então, tratar à internet como forma de inserção social e como um serviço que pode, também, ser disponibilizado de forma pública.

Presente em cafés, lojas, prédios comerciais, praças ou em residências, seja em locais públicos ou privados, a tecnologia $\mathrm{Wi}$-Fi expande-se de forma exponencial pelo espaço urbano. É comum, na paisagem das grandes metrópoles contemporâneas, vermos pessoas conectadas - seja em laptops, celulares ou tablets, a redes sem fio com fins os mais diversos (trabalho, lazer, estudo). Associada a outros tipos de conexão sem fio, como a internet $3 \mathrm{G}$, por exemplo, o $802.11 \mathrm{~b}$ wireless local area networking configura-se como um dos responsáveis por transformar as relações do ciberespaço com o espaço urbano.

Pessoas passam a valorizar espaços que ofereçam possibilidades de conexão à internet, produzindo assim novos sentidos dos lugares (LEMOS, 2010). A rede torna-se ubíqua, de forma a ampliar, junto com o constante desenvolvimento de tecnologias móveis, as possibilidades de conexão, permitindo maior mobilidade física (pessoas, objetos, commodities) e informacional (informação midiática, arquivos, softwares). As tecnologias digitais e as redes telemáticas sem fio, portanto, vêm criando novas formas de interação com os lugares. Observa-se uma cidade cada vez mais desplugada, permitindo conexões em mobilidade, numa "era da conexão", na qual "novas práticas e novos usos 
do espaço urbano vão, pouco a pouco, constituindo os lugares" (LEMOS, 2005, p.9).

Os atuais estudos em cibercultura mostram que não existem relações sociais sem enraizamento local e que as redes, enquanto espaço/lugar de socialização, de circulação de informação e de vínculos comunitários não estão situadas em um mundo a parte. O que acontece nas redes tem/é fruto de repercussões concretas de tudo que nos vincula às dimensões quotidianas e locais da experiência. As redes telemáticas, e as sem fio particularmente, criam novos processos de territorialização, criando novas significações nos lugares. $O$ espaço deve ser então pensado em sua dimensão concreta e abstrata a partir dos novos media: como rearranjo dos lugares, como mundo virtual imaginário, como o urbano reapropriado temporariamente onde as infraestruturas de redes e acesso que criam territórios informacionais, fusionando lugar e ciberespaço.

Um dos exemplos pioneiros, e que caracteriza bem a difusão do uso da internet em locais públicos, é o cibercafé. Surgindo no início dos anos 1990, a ideia de acoplar num mesmo lugar serviços de acesso à internet e cafeteria produz uma reconfiguração do lugar (a cafeteria) produzindo novas funções, informacionais, que passam a atrair um público frequentador dos cafés e também da internet para os mais diversos usos (redes sociais, e-mail, pesquisa etc.). Alia-se aqui espaço físico e eletrônico criando uma atividade social (LIFF; STEWARD, 2003). Segundo esses autores, como se tratavam de tecnologias recentes para o público em geral, permitir um acesso fácil a elas, associado a uma prática tão rotineira como tomar um café, tornam-nas mais populares, criando uma comunidade de usuários que, muitas vezes, se auxiliam mutuamente para o uso de computadores e da internet.

O surgimento dos cibercafés no início dos anos 1990 coincide justamente com o crescimento no interesse em políticas públicas para difusão do acesso à internet (LIFF; STEWARD, 2003). Os lugares, oferecem estruturas que possibilitam conexão à rede, seja em um cibercafé ou numa praça, criam novas "heterotopias", fazendo analogia ao termo de Foucault (1984), podendo ser interpretado aqui como funções reais dos lugares, diferente das "utopias". As 
novas mídias refuncionalizam os lugares do espaço urbano criando novas heterotopias:

Um tipo especial de lugar - a heterotopia - é destacado nas análises de Foucault. É um tipo de lugar possuindo uma "interessante característica" de uma relação única com outros lugares que a possibilita "suspeitar, neutralizar ou inverter o conjunto de relações" que aqueles outros lugares "designam, espelham e refletem". Esses lugares de heterotopia existem como "lugares reais" que são "conectados", em contradição com todos os lugares (LIFF; STEWARD, 2003, p.318, tradução nossa).

Cada vez mais, os lugares passam a ter uma dimensão fundamental na cibercultura, diferente da perspectiva tão em voga nos anos 1990 que sustentava que a internet substituiria as relações locais e enfraqueceria as dimensões físicas do espaço urbano. Com as tecnologias e redes telemáticas digitais e sem fio vemos justamente o contrário. A emergência de mídias de geolocalização (GPS associados a mapas digitais e ferramentas como Places, Foursquare, Gowalla, Spotsquare, Everyblock), mostram bem esse novo estado. São lugares que se relacionam com diversos outros lugares ${ }^{1}$, através da relação das pessoas com o ambiente físico e o ciberespaço.

Com a difusão posterior das redes sem fio, como o $\mathrm{Wi}$-Fi, as interseções entre os lugares e a internet intensificam-se, apesar de torná-las cada vez mais invisíveis e pervasivas². Os cafés, por exemplo, continuam sendo um forte lugar de encontro e de uso da internet, porém não disponibilizam mais necessariamente bancadas com computadores para público; basta uma conexão Wi-Fi e laptops. Na verdade, estampar no nome a relação de "café" e "ciber" deixa de ter sentido, já que qualquer lugar na cidade pode vir a ser um ambiente de conexão. No caso dos cafés, passou a ser

\footnotetext{
${ }^{1}$ Ver sobre as dimensões locais e globais, a perspectiva de Bruno Latour (2005), principalmente no capítulo "Second Move: Redistributing the Local", pp. 191 e seguintes.

2 A ideia de computação "pervasiva" vem da proposta de computação ubíqua de Mark Weiser, proposta nos anos 1990 e que afirmava o surgimento de uma computação "calma" na qual os computadores desapareceriam nos objetos e as redes tornaríam-se ubíquas. Ver Weiser, 1991.
} 
comum não mais a existência de grandes computadores ocupando parte do espaço, mas clientes sentados em mesas com seus próprios aparelhos móveis, como notebooks, smartphones ou tablets.

\section{Territórios informacionais}

Com tais dispositivos móveis, aliados às redes sem fio, percebe-se a constituição de processos territorializantes. Com as redes Wi-Fi, o lugar ocupado socialmente passa a ter uma nova função informacional, um novo território, numa zona de intersecção e controle (daí o termo território) entre o ciberespaço e o lugar urbano, reconfigurando-o. Essa zona pode ser compreendida como um "território informacional" que amplia as funções sociais dos lugares constituídos como um café, uma praça, uma sala de aula, etc. Segundo Lemos,

O território informacional não é o ciberespaço, mas o espaço movente, híbrido, formado pela relação entre o espaço eletrônico e o espaço físico. Por exemplo, o lugar de acesso sem fio em um parque por redes Wi-Fi é um território informacional, distinto do espaço físico parque e do espaço eletrônico internet. Ao acessar a internet por essa rede Wi-Fi, o usuário está em um território informacional imbricado no território físico (e político, cultura, imaginário, etc.) do parque, e no espaço das redes telemáticas (LEMOS, 2007, p. 12-13).

Essa redefinição dos lugares, a partir da presença de um território informacional a permear o espaço físico, faz com que as pessoas criem formas diferentes de lidar com ele. Atualmente, as pessoas começam a internalizar a infraestrutura da rede nos espaços públicos e privados (MACKENZIE, 2005) e já cobram e acham "natural" ter uma zona de conexão à internet nesses lugares, assim como é "natural", encontrar infraestrutura de energia elétrica, água ou esgotamento sanitário.

O território informacional é uma zona de controle, sendo nesse caso um controle das informações digitais que circulam através de redes sem fio em sinergia com lugares específicos. Um exemplo dessa territorialização pode ser observado quando uma rede sem fio é fechada; ou seja, só se permite o acesso àqueles que possuam uma senha específica. Trata-se de uma situação comum 
em estabelecimentos comerciais que apenas liberam o uso da rede após algum tipo de consumo por parte do cliente ou em redes de uso domiciliar. Por outro lado, há aqueles locais onde o acesso ao território informacional é totalmente livre, sem necessitar de nenhum tipo de senha ou identificação. Em alguns outros, a rede é desligada em alguns períodos do dia, demonstrando ainda mais como os lugares são reconfigurados ${ }^{3}$. De uma forma ou de outra, o controle se exerce, seja exigindo uma senha, seja deixando a zona aberta. Sempre há um controle do tráfego, um log dos "IPs", etc. Os protocolos da rede (GALLOWAY, 2004) a configuram como território de controle, mesmo que isso não signifique um constrangimento total do uso.

Essa associação de tecnologias móveis com uma rede telemática ubíqua faz com que haja, também, mudanças na forma como as pessoas lidam com os lugares. Em um estudo sobre como objetos portáteis modificam as relações entre pessoas e delas com o espaço urbano, realizado em diferentes metrópoles como Tóquio, Los Angeles e Londres pelos pesquisadores Mizuko Ito, Daisuke Okabe e Ken Anderson (2007), observaram-se tipos de comportamentos a partir do uso do celular ou do notebook, por exemplo, em áreas públicas.

Foram identificados três gêneros de presença no espaço urbano: cocooning, camping e footprinting. $\mathrm{O}$ primeiro relaciona-se com a ideia de fechar-se em uma espécie de bolha para evitar a interação com outras pessoas ou o meio, numa certa apropriação do espaço público para uso pessoal. São "micro-lugares construídos por meio de privados, infraestruturas controladas individualmente, temporariamente apropriando-se de espaços públicos para uso pessoal" (ITO; OKABE; ANDERSON, 2007, p.7, tradução nossa). Esse tipo de presença estaria associado principalmente ao transitar, em transportes públicos ou caminhando, a partir de music players, smartphones ou até materiais de leitura, por exemplo. Já o camping

\footnotetext{
${ }^{3} \mathrm{O}$ Shopping Barra em Salvador, por exemplo, desliga a rede Wi-Fi das $12 \mathrm{~h}$ às $14 \mathrm{~h}$ para evitar que as pessoas ocupem as mesas da praça de alimentação para uso apenas da rede. Alguns cafés desligam a rede para que as pessoas possam interagir mais entre elas e menos com seus laptops. Esses exemplos mostram como a territorialização informacional altera as funções locativas do espaço.
} 
estaria mais associado a uma apropriação de fato dos lugares, quando as pessoas produzem um certo tipo de acampamento ao carregarem mídias portáteis consigo. Segundo os autores, "o atrativo de trabalhar em um 'lugar de acampamento' específico pode incluir relações pessoais criadas ali, comida e bebida, infraestrutura (mesas, eletricidade, $\mathrm{Wi}$-Fi), e mais importante, ambiente social difuso" (ITO; OKABE; ANDERSON, 2007, p.10, tradução nossa). Então, ambientes com territórios informacionais amplos, numa boa estrutura wireless, costumam atrair campers; é o caso, novamente, dos cafés, onde se pode associar serviços de comida, bebida e Wi-Fi.

Além disso, esses usuários ainda podem deixar marcas, footprints, a partir de interações com territórios informacionais. Os autores, ao observar a proliferação de diferentes cartões de fidelidade nas carteiras dos participantes da pesquisa, perceberam a utilização de alguns tipos de serviços baseados em localização para mediar suas relações com o espaço urbano. Por isso, "o processo de manter gravações de dados de transações de consumidores pode ser considerado um processo de 'footprinting' ou deixar rastros em um local em particular” (ITO; OKABE; ANDERSON, 2007, p.10, tradução nossa).

Dessa forma, percebe-se que a associação das tecnologias móveis com redes cada vez mais ubíquas, através, por exemplo, de conexões $\mathrm{Wi}$-Fi ou $3 \mathrm{G}$, potencializam as relações com os lugares e entre os indivíduos. Trata-se de compreender as relações entre as novas mídias digitais e os processos de espacialização em jogo no atual momento da sociedade da informação (mobilidade, geolocalização, conexão ubíqua).

\section{Wi-Fi no Brasil: entraves e projetos}

As redes sem fio estão crescendo de forma exponencial no Brasil e no Mundo. É difícil apresentar estatísticas fidedignas já que a adoção de redes sem fio em estabelecimentos comerciais, públicos e privados cresce a cada dia. Colocar um roteador sem fio em uma conexão à internet se transformou em um ato banal. Assim, as redes sem fio começam a fazer parte do cotidiano, seja em ambiente doméstico, de trabalho ou de lazer. Cada vez 
mais, estabelecimentos comerciais e espaços como universidades, bibliotecas, livrarias, etc. oferecem serviço de internet sem fio gratuitamente ou com alguma taxa sobre o serviço. É muito difícil oferecer qualquer dado sobre a expansão do Wi-Fi no país, mas podemos dizer que a tendência é que cada conexão à internet venha a ter, em um curto espaço de tempo, um roteador sem fio acoplado, transformando-a em uma conexão Wi-Fi.

Percebendo esta demanda cada vez maior, o Governo Federal, em conjunto com os governos estaduais, vem pensando em projetos e mecanismos para difundir o acesso à informação para a população brasileira. Estes projetos devem levar em consideração as leis nacionais, reguladas pela Anatel, promovendo a inclusão digital de comunidades sem acesso à internet. Para Fabio Josgrilberg (2009), é necessário que se tome o cuidado de não inibir o desenvolvimento do setor de telefonia nos locais contemplados pelos projetos: uma rede totalmente pública, para ele, "pode inibir o desenvolvimento local do setor, pode indicar menor criação de empregos e reduzir a velocidade das inovações, que, em geral, se favorecem pela competição entre empresas" (2009, p. 25). O autor ainda afirma que um projeto de rede municipal sem fio deve envolver várias dimensões que precisam estar muito bem articuladas, a saber: a) o envolvimento da comunidade na organização e desenvolvimento do projeto; b) condições estabelecidas para a tomada de decisões e a transparência desta governança; c) a infraestrutura disponibilizada para os projetos e d) o modelo de negócio utilizado (privado, público, franquia, empresa-âncora ou comunitário). Todos estes fatores são importantes para, por exemplo, manter a neutralidade da rede e garantir um acesso igualitário para as populações participantes dos projetos.

Alguns projetos de redes sem fio públicas já estão em vigor, em algumas cidades, bairros e localidades espalhadas por todo o país. Em artigo que pretendia demonstrar os benefícios das "nuvens abertas de conexão", Silveira (2009) estudou os casos de Sud Menucci (SP), Quissamã (RJ) e Tapira (MG). Em todas estas cidades, com menos de 20.000 habitantes e com seus territórios totalmente cobertos por redes $\mathrm{Wi}$-Fi públicas (um território informacional municipal, poderíamos dizer), houve um enorme crescimento do 
acesso à internet após a implantação dos projetos: em Tapira, este crescimento foi de 6 vezes; em Quissamã, chegou a 8; e em Sud Menucci, 28 vezes mais famílias passaram a acessar a internet após a implantação dos hotspots (pontos de acesso a internet sem fio). Ainda segundo Silveira, o grande aumento na conectividade da população se deve à implantação do sinal Wi-Fi nas cidades. De acordo com o autor, "a formação de nuvens abertas de conexão no Brasil pode incentivar não somente a aquisição de computadores como também a conectividade" (2009, p. 41). O incentivo ao acesso à internet tem um cunho social, ao passo que "o potencial de conexão no país é bloqueado por fatores sociais e econômicos" (SILVEIRA, 2009, p. 38). A popularização das redes sem fio públicas pode ajudar a aumentar a concorrência entre as empresas de telefonia, o que pode significar aumento na qualidade dos serviços prestados e queda no preço da conectividade. Em 2007, em levantamento feito pela Associação Brasileira de Prestadoras de Serviços de Telecomunicações Competitivas, o megabit chegou a ser vendido por $\mathrm{R} \$ 716,50$ por mês no Brasil, contra o equivalente a $\mathrm{R}$ \$ 4,32 mensais na Itália, $\mathrm{R}$ \$ 5,02 na França e $\mathrm{R}$ \$ 12,75 nos Estados Unidos da América (SILVEIRA, 2009, p.38).

Como afirma Josgrilberg (2009), baseando-se em discussões anteriores elaboradas pelo geógrafo Milton Santos (1979), a oferta de acesso à internet patrocinada pelos governos é um fator estimulante da democracia.

A pobreza, explica o geógrafo, é, acima de tudo, uma definição política que tem a ver com os objetivos que uma sociedade determina para si (SANTOS, 1979). Portanto, a pobreza não é simplesmente um dado estatístico com ênfase na renda e definições de linhas de miséria ou coisa que o valha. $\mathrm{Na}$ chamada Sociedade do Conhecimento, o acesso à Internet em banda larga e, por que não, sem fio, deve fazer parte de qualquer definição possível de pobreza. Como se sabe, hoje, salvo raras exceções, a banda larga chega apenas onde há mercado, ou seja, consumidores em condições de comprar os serviços oferecidos pelas empresas de telecomunicações (JOSGRILBERG, 2009, p.25).

$\mathrm{Na}$ Bahia, alguns projetos públicos voltados para o estabelecimento de cidades digitais começam a ser colocados em prática, nas maiores cidades do Estado, como o Feira Digital ${ }^{4}$, em Feira de

${ }^{4}$ http://www.feiradigital.ba.gov.br/ 
Santana (segunda maior cidade baiana, com 591.707 habitantes segundo último levantamento do IBGE), que disponibiliza acesso a rede sem fio num raio de 500 metros em sete localidades do município, como bairros populares e uma parte do centro. Em Salvador, capital do estado, a prefeitura instalou recentemente cerca de 50 totens pela cidade ${ }^{5}$, disponibilizando acesso sem fio através de alguns deles em um raio de 300 metros.

Outro projeto interessante é o Madre Digital ${ }^{6}$, iniciativa da prefeitura de Madre de Deus, cidade de 15.432 mil habitantes, que implantou internet gratuita para toda a sua população. Madre de Deus é um município que fica a $63 \mathrm{~km}$ de Salvador, localizado em uma das ilhas da Baía de Todos os Santos, separada a 100 metros do continente. A população do município se aloca em uma área de $11 \mathrm{~km}^{2}$, ou seja, produzindo densidade demográfica de 1.385,1 habitantes por $\mathrm{km}^{2}$. A cidade é uma das maiores produtoras de petróleo do estado, o que explica o alto PIB e a alta concentração de impostos. De acordo com informações da prefeitura da cidade, desde 2005 o município mostrou-se interessado em planos de inclusão digital.

O projeto inicial consistia em oferecer o sinal WI-FI para interligar as escolas municipais. Em seguida, a prefeitura estendeu o acesso a todo o município, massificando o acesso à internet em prédios públicos, escolas, centros sociais, unidades de saúde e na ilha de Maria Guarda, a partir de uma rede de telecomunicação municipal. Em junho de 2009, foi inaugurado o projeto Madre Digital, fornecendo internet gratuita para a população, através de tecnologia WI-FI.

Para obter acesso ao projeto, a prefeitura da cidade solicita uma pré-inscrição dos moradores interessados a partir de um e-mail enviado ao endereço madredigital@madrededeus.ba.gov.br, no qual deve ser solicitado o usuário e a senha com os seguintes dados: nome completo, endereço, telefone, e-mail e o meio atra-

\footnotetext{
${ }^{5}$ http://www.sucom.ba.gov.br/noticias/salvador-ganha-totens-com-servi\%C3\% A7os-de-utilidade-p\%C3\%BAblica.aspx

${ }^{6}$ http://www.madrededeus.ba.gov.br/index.php?link=visualiza_noticia\&id_noticia $=92$
} 
vés do qual o cidadão irá acessar o serviço (desktop, notebook, celular ou outros dispositivos). Além de democratizar o acesso à informação, projetos como o Madre Digital evidenciam como tecnologias da informação e comunicação - neste caso, as redes sem fio - recuperam a importância dos lugares, ao atrelarem a conectividade à utilização do ambiente físico e informacional. Tal vínculo com o espaço, mediado pelas tecnologias, também pode ser observado na concepção e na utilização dos mapas colaborativos, como veremos a seguir.

\section{Mapas colaborativos: o caso do Wi-Fi Salvador}

Atualmente, no âmbito das mídias locativas e das tecnologias colaborativas, os mapas online se encontram num momento de popularização e sofisticação de seus aparatos. A partir do advento das tecnologias Google Maps e Google Earth, no meio dos anos 2000, a cartografia online está cada vez mais popular entre os usuários da internet.

Os mapas colaborativos, criados com a participação dos usuários, não são apenas utilizados para geolocalização; são também tecnologias de construção de discursos múltiplos, "conversacionais", de baixo para cima, que ajudam a "reescrever" as cidades de um modo multidirecional, onde o fluxo de informação pode não obedecer à mesma ordem das mídias massivas, mas funcionar como função pós-massiva (LEMOS, 2007). Segundo Lemos (2007), a função massiva é dirigida à massa, dispersa em diferentes locais do globo e com pouca possibilidade de interação. Para ele, esta função atua como "um fluxo centralizado de informação, com o controle editorial do pólo da emissão, por grandes empresas em processo de competição entre si, já que são financiadas pela publicidade" (LEMOS, 2007, p.4). A correlação entre mapa tradicional - mídia de massa e mapa digital - mídias pós-massivas pode ser assim estabelecida.

Mídias de função pós-massiva atuam sob um regime diferente: a principal diferença entre elas é que todos podem produzir, distribuir e receber informação, em um modelo "todos para todos" (LÉVY, 1999), diferente do fluxo unidirecional, "de cima para bai- 
xo", das mídias massivas. Neste sentido, mapas colaborativos têm sido utilizados com diversos propósitos: publicidade, informações de utilidade pública, complementação de notícias em diferentes áreas do jornalismo, denuncia sobre problemas no espaço urbano, visibilidade de práticas sociais, de pontos de interesse, etc. Os exemplos são diversos ${ }^{7}$ : cobertura das chuvas em metrópoles brasileiras, mapeamento dos buracos em Fortaleza ${ }^{8}$, mapeamentos de sons urbanos, de ciclovias e estacionamento de bicicletas, de pontos de interesse e de crimes (BRUNO, 2009), entre outros.

É interessante ver como as novas potencialidades das ferramentas eletrônicas digitais podem ajudar a revelar os rastros sociais, as relações efetivas nos lugares do espaço urbano, ajudando assim a repensar o espaço vivido. Os mapas devem ser vistos como mídias, trazendo tensões entre localização e mobilidade. Com as novas funções pós-massivas dos mapas digitais, oferece-se a oportunidade de produção coletiva e colaborativa de criação de cartografias locais onde as pessoas podem acessar e anotar posições no espaço. O objetivo é identificar as relações sociais, culturais e de poder entre os diversos "actantes" (LATOUR, 2005) para questionar hierarquias e as formas de habitarmos o mundo.

Para Heidegger "les espaces que nous parcourons journellement sont 'ménagés' par des lieux" (HEIDEGGER, 1958, p.186). A essência do homem é residir, construir (um lugar) para habitar e é o construir que funda os lugares e articula os espaços. O lugar é assim o espaço socialmente produzido. Mais ainda: "les espaces reçoivent leur être des lieux et non de 'l'espace" (HEIDEGGER, 1958, p. 183). O “outro" espaço, que não é o espaçamento entre os lugares, é um abstractum matemático. Nesse espaço não encontramos lugares. O construir funda os lugares e articula espaços.

Percorrer e navegar é produzir relações entre as coisas construídas. $\bigcirc$ mapeamento pode aqui revelar dimensões ontológicas, políticas, culturais, sociais e econômicas desse "habitar". O lugar é o espaço socialmente produzido, e é ele que "arruma", que cria o

\footnotetext{
${ }^{7}$ http://ciberalgo.wordpress.com/2010/07/30/usos-de-mapas-em-comunicacao-digital/

${ }^{8}$ http://gpc.andrelemos.info/blog/?p=359
} 
espaço (Heidegger, 1958). Os mapas, tradicionalmente, buscavam um mimetismo com o espaço abstrato. Os mapas digitais podem revelar relações, conexões, movimentos entre as coisas no mundo construído (lugares). Mapas representativos (miméticos) não dizem nada sobre os lugares, são "panoramas", não fazem correlações e fixam apenas generalizações. Mapas digitais colaborativos abrem a perspectiva de cartografias "não-miméticas", navegacionais, menos representativas de um contexto (espaço). Eles podem nos ajudar a problematizar questões relativas ao habitar entre as coisas construídas (lugares).

\section{Wi-Fi Salvador}

Um exemplo pioneiro no mapeamento colaborativo brasileiro e especificamente no que se refere a redes Wi-Fi é o projeto Wi-Fi Salvador criado em 2006 pelo Grupo de Pesquisa em Cibercidade (GPC) do Programa de Pós-Graduação em Comunicação e Cultura Contemporâneas (PPGCCC) da Faculdade de Comunicação (Facom) da Universidade Federal da Bahia (UFBA) ${ }^{9}$. O Projeto Wi-Fi Salvador ${ }^{10}$ tem como objetivo mapear de forma colaborativa os pontos de conexão à internet sem fio (hotspots $\mathrm{Wi}_{i}$-Fi) da cidade de Salvador, Bahia.

Oficialmente, o projeto foi lançado em agosto de 2007 no Ciclo Internacional de Debates sobre Cibercultura ${ }^{11}$, quando já contava com 50 locais cadastrados. Pretendia-se, assim, não apenas divulgar as possibilidades de conexão sem fio pela cidade e facilitar a localização de pontos Wi-Fi, tornando, de certa forma, visíveis os territórios informacionais, como também pensar o uso do espaço urbano, a reconfiguração dos lugares e os novos processos de espacialização em jogo com as redes sem fio e as tecnologias

\footnotetext{
${ }^{9}$ http://gpc.andrelemos.info/blog/ ${ }^{10}$ http://blog.ufba.br/wifisalvador

${ }^{11}$ Evento realizado em parceira da PPGCC/Facom/UFBa com o ICBA, em Salvador, Bahia, agosto de 2007.
} 
móveis como laptops e smartphones. Um dos objetivos do projeto é oferecer um mapeamento que possa servir para estudos futuros sobre espacialidade, redes sem fio, mobilidade, espaço urbano e tecnologias portáteis em Salvador.

O sistema é colaborativo e participativo no qual qualquer pessoa pode indicar um hotspot e enviar, inclusive, fotos, vídeos, sons ou impressões dos lugares, de forma a associar experiências diretas em espaços de convivência pública nos quais existe acesso à internet. A cada envio a equipe responsável checa e publica a informação no mapa (ver abaixo ${ }^{12}$ ). O Wi-Fi Salvador não permite uma colaboração direta a fim de evitar erros ou alteração não desejada no mapa.

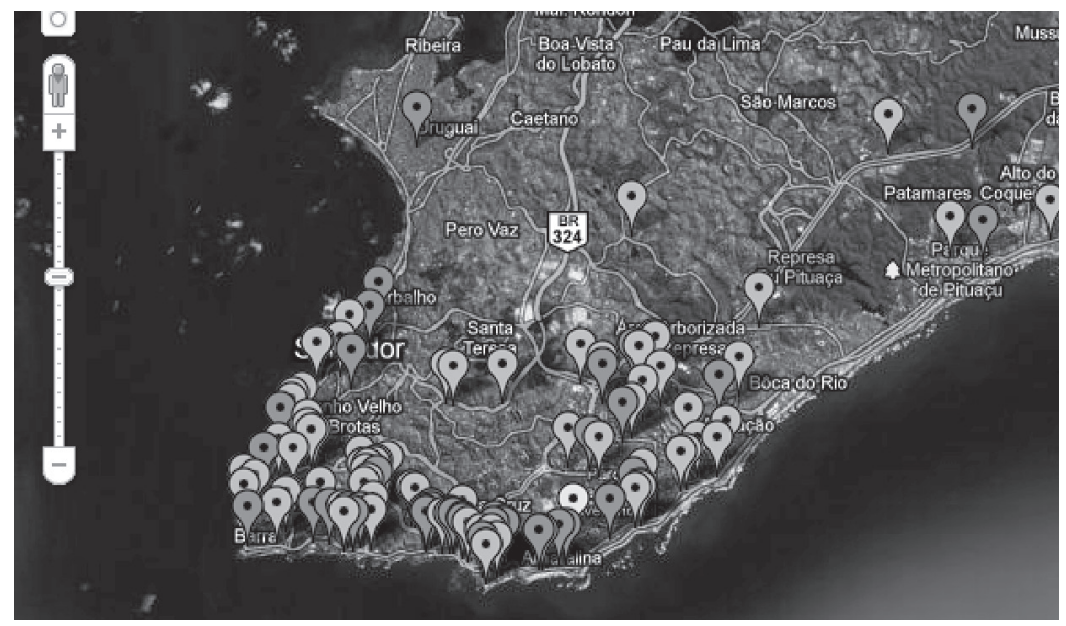

Mapa dos hotspots em Salvador. Pontos verdes são de livre acesso, pontos vermelhos de conexão fechada e pontos amarelos de conexão doméstica aberta. (GPC/Facom/UFBa, 2010).

Em um primeiro momento, as atualizações eram sugeridas por e-mail ou pelo blog do GPC. O Wi-Fi Salvador foi reestruturado em 2010, passando a aceitar colaborações via Twitter. Basta o usuário enviar uma mensagem para @wifi_salvador ou utilizar a hashtag

${ }^{12}$ Mapa disponível em https://blog.ufba.br/wifisalvador/ 
\#wifi_salvador. Dessa forma, conseguiu-se aumentar o número de hotspots para 123, sendo 83 de conexão aberta, 39 fechada e 1 hotspot doméstico ${ }^{13}$. Trata-se, portanto, do maior mapeamento colaborativo de redes wireless já realizado em Salvador e no Brasil.

A nova reformulação, realizada em 2010, permitiu que os participantes interagissem melhor com o projeto. A conta no Twitter incentivou a participação. Desta forma, o número de seguidores cresceu e alguns usuários passaram a contribuir de forma mais dinâmica através do microblog. Cada sugestão de novo hotspot, pago ou gratuito, passou a ser incluído através do Google Maps, atualizando diretamente no site do projeto. Em seguida, divulgamos no@wifi_salvador cada novo ponto mapeado, dando crédito ao usuário que lhe indicou. A rede expandiu e a colaboração cresceu substancialmente desde então.

Alguns dos novos hotspots mapeados, porém, não vieram de colaborações, mas da nossa observação direta. Utilizando smartphones ou notebooks, os pesquisadores conferiam se era possível um acesso Wi-Fi em algum local específico. Congestionamentos no tráfego da cidade, ao passo que atrapalham na mobilidade da população, acabavam ajudando a detectar onde havia redes sem fio, já que o trânsito parado permitia que as redes fossem acessadas e averiguadas com mais calma. Essa técnica de wardriving foi e continua a ser utilizada para mapeamento de novos hotspots na cidade. O próximo objetivo do GPC é transformar o Wi-Fi Salvador em um aplicativo para smartphone fazendo com que o acesso à informação possa se dar de forma mais simples e em mobilidade pelos usuários em busca de "territórios informacionais" soteropolitanos.

Em espaços comerciais, como cafés ou lanchonetes, por exemplo, caso a rede fosse fechada, os pesquisadores perguntavam se a senha era distribuída para clientes ou não. Em alguns casos, a conexão é realizada apenas de forma paga via $\mathrm{Vex}^{14}$, como no Aeroporto Internacional de Salvador, enquanto em outros o acesso

\footnotetext{
${ }^{13}$ Dados de 06/09/2010

${ }^{14}$ Vex é uma empresa que fornece serviços de conexão Wi-Fi em locais públicos a partir do pagamento de planos mensais, de 24 horas ou duas horas. Além do Brasil, está presente em outros 56 países. http://www.vexcorp.com/
} 
é livre e gratuito, como no foyer do Teatro Castro Alves. Todos esses detalhes, evidentemente, são descritos e associados aos pontos mapeados. Em alguns momentos, os pesquisadores fizeram o mapeamento imediatamente, diretamente do local, acessando o serviço do Google Maps através do hotspot que estava sendo mapeado. Essa dinâmica, inclusive, é muito usada pelos colaboradores. Estando exatamente na localidade que desejam mapear, os usuários nos enviam as referências via Twitter, para que estas sejam posteriormente acrescentadas ao mapa do Wi-Fi Salvador. O sucesso da nova fase se deu exatamente por essa facilidade agregando mobilidade física (o deslocamento do usuário) e informacional (o uso de tecnologias móveis em "territórios informacionais" para o envio das informações).

Há, porém, outros projetos no Brasil que utilizam mapeamento colaborativo para hotspots. É o caso do Mapa Wi-Fi ${ }^{15}$ e do Sinal $3 \mathrm{G}^{16}$. O primeiro baseia-se justamente no mapeamento de redes Wi-Fi, tendo, porém, abrangência nacional. Nesse caso, os hotspots cadastrados em Salvador não ultrapassam 25, enquanto o Wi-Fi Salvador disponibiliza mais de 120 pontos para consulta. Já o Sinal $3 \mathrm{G}$ trabalha com a ideia de permitir aos usuários de internet $3 \mathrm{G}$, independente da operadora de telefonia, divulgar quais locais da cidade oferecem uma melhor ou pior conexão. Assim como o outro projeto, a relevância para Salvador é mínima, com menos de dez pontos cadastrados.

\section{Considerações finais}

A cidade contemporânea é uma cidade de ampla conexão, associando espaço físico e "territórios informacionais" para os mais diversos fins. Alia-se aqui mobilidade física e informacional. Mostramos os principais desafios teóricos em jogo com as mídias digitais, as redes sem fio e o espaço urbano. As ciências da comunicação devem dar mais atenção aos processos midiáticos de espacialização com as novas mídias.

\footnotetext{
${ }^{15}$ http://www.mapawifi.com.br

${ }^{16}$ http://www.sinal3g.com.br/
} 
O exemplo dos cibercafés serviu para explicarmos as noções de "heterotopia" e território informacional mostrando que as redes telemáticas sem fio criam novas tensões entre espaço físico e informacional. Descrevemos rapidamente a situação da implementação de redes sem fio no Brasil, chamando a atenção para questões estratégicas, políticas e sociais (inclusão digital) nas cidades brasileiras que adotam essas redes como política pública. Por último, explicamos as principais características dos mapas digitais, revelando as potencialidades sociais (rastreamento dos vínculos reais nos lugares do espaço urbano) e políticas dos mapeamentos participativos e colaborativos. Para exemplificar essa parte tomamos como referência o projeto Wi-Fi Salvador.

Experiências como as do Wi-Fi Salvador tornam visíveis os territórios informacionais formados pelas conexões wireless revelando novos sentidos do lugar e novos processos espacializantes. A pesquisa mostra como a intersecção entre o ciberespaço e o espaço físico está trazendo novas experiências de uso e de produção de sentido sobre a cidade. Ao encontrarem um hotspot, os usuários atuam a partir de um "território informacional", acionam tecnologias digitais móveis, softwares e bancos de dados, produzem informação locativa em mapas sobre o espaço físico em uma sinergia produtora de novas experiências locais. A colaboração em rede de outras pessoas, especialmente através do Twitter, ajudou o sentimento de pertencimento e foi fundamental para o crescimento do Wi-Fi Salvador, mantendo-o hoje como o maior mapeamento de redes sem fio já realizado na capital baiana e no Brasil.

\section{Referências}

ADAMS, P. Geographies of media and communication. Malden: Wiley-Blackwell, 2009.

ASSOCIAÇÃO BRASILEIRA DE PRESTADORAS DE SERVIÇOS DE TELECOMUNICAÇÕES COMPETITIVAS. Procedimentos administrativos. 2007.

Disponível em: http://www.telcomp.org.br/Publicacoes/PROCED_ADM_ TELCOMP_04julho2007.pdf Acesso em: 10 abr. 2012. 
BRUNO, F. Mapas de crime: vigilância distribuída e participação na cibercultura. In: XVIII ENCONTRO DA COMPÓS, 2009, Belo Horizonte. Anais eletrônicos... Disponível em http://www.compos.org.br/data/biblioteca_1170. pdf. Acesso em: 10 abr. 2012.

FALKHEIMER, J.; JANSSON, A. Geographies of communication. The spatial turn in media studies. Gottemborg: Nordicom, 2006.

FOUCAULT, Michel. De outros espaços. Architecture, Moviment, Continuité, 5, 1984. Disponível em: http://www.ufrgs.br/corpoarteclinica/obra/outros. prn.pdf Acesso em: 10 abr. 2012.

GALLOWAY, Alexander. Protocol - how control exists after decentralization. Massachusetts: The MIT Press, 2004.

HEIDEGGER, M. Essais et conférences. Sueil, Gallimard, 1958.

ITO, M. Network localities: identity, place, and digital media. Draft, s.d. Disponível em http://citeseerx.ist.psu.edu/viewdoc/summary?doi=10.1.1.17.2526 Acesso em: 10 abr. 2012.

ITO, M.; OKABE, D.; ANDERSON, K. Portable objects in three global cities: the personalization of urban places. The Mobile Communication Research Annual, [s.l.: s.n.], 2007. Disponível em: www.itofisher.com/mito/portableobjects.pdf. Acesso em: 10 abr. 2012.

JOSGRILBERG, Fabio. Redes municipais sem fio: o acesso à internet e a nova agenda da cidade. In: LEMOS, A.; JOSGRILBERG, F. (Orgs.). Comunicação e mobilidade. Salvador: EDUFBA, 2009. p. 19 - 36. Disponível em: http:// poscom.ufba.br/arquivos/livro_Comunicacao_Mobilidade_AndreLemos.pdf

LATOUR, B. Reassembling the social. Oxford: Oxford University Press, 2005.

LEMOS, André. Post-mass media functions, locative media, and informational territories: new ways of thinking about territory, place, and mobility in contemporary society. In: Space and Culture. Thousand Oaks; London: Sage, v. 13, p. $403-420$, nov. 2010 .

LEMOS, André. Cibercultura e Mobilidade: A Era da Conexão. In: XXVIII CONGRESSO BRASILEIRO DE CIÊNCIAS DA COMUNICAÇÃO, 2005. Rio de Janeiro. Anais eletrônicos... Disponível em: http://www.intercom.org. br/papers/nacionais/2005/resumos/R1465-1.pdf Acesso em: 10 abr. 2012. 
LEMOS, André. Mídia locativa e territórios informacionais. In: XVI ENCONTRO DA COMPÓS, 2005. Curitiba. Anais eletrônicos... Disponível em: http://www.compos.org.br/data/biblioteca_168.pdf Acesso em: 10 abr. 2012.

LÉVY, Pierre. Cibercultura. São Paulo: Editora 34, 1999.

LIFF, Sonia; STEWARD, Fred. Shaping e-acecess in the cybercafé: networks, boundaries and heterotopian innovation. New Media y Society, Thousand Oaks/London, v. 5, n. 3, p. 313-334, 2003. Disponível em: http://nms.sagepub.com/content/5/3/313.full.pdf + html . Acesso em: 10 abr. 2012.

MACKENZIE, Adrian. Untangling the Unwired: Wi-Fi and the Cultural Inversion of Infraestructure. Space and Culture,Thousand Oaks / Londres, v. 8, n. 3, p. 269-285, 2005. Disponível em: http://sac.sagepub.com/content/8/3/269.full.pdf+html Acesso em: 10 abr. 2012.

SILVEIRA, S. A. Espectro aberto e mobilidade para a inclusão digital no Brasil. In: LEMOS, A.; JOSGRILBERG, F.(Orgs.). Comunicação e mobilidade. Salvador: EDUFBA, 2009. p. 37-50. Disponível em:

http://poscom.ufba.br/arquivos/livro_Comunicacao_Mobilidade_AndreLemos. pdf. Acesso em: 10 abr. 2012.

WEISER,M. The computer for the 21st century. Scientific American, New York, v.3, n. 265, p.94-104, 1991. Disponível em: http://nano.xerox.com/ hypertext/weiser/SciAmDraft3.html . Acesso em: 10 abr. 2012.

WIRELESS GLOSSARY. Computer World. [s.l: s.n.], 19 out. 2005. Disponível em: http://www.computerworld.com/mobiletopics/mobile/ story/0,10801,92873,00.html. Acesso em: 10 abr. 2012.

Recebido: 07.12.2011

Aceito: 25.4.2012 